\title{
Neurological risk profile in organic erectile impotence
}

\author{
E Kunesch, K Reiners, V Müller-Mattheis, T Strohmeyer, R Ackermann, H-J Freund
}

\begin{abstract}
Thirty men who presented with erectile impotence to the urological department underwent a thorough urological, angiological, and neurological examination with complementary neurophysiological tests of somatosensory and sympathetic and parasympathetic function. Most had vascular and neurological abnormalities. Clinical findings and electrophysiological tests for autonomic dysfunction had the highest yield of abnormal results. Nerve conduction studies and pudendal nerve somatosensory evoked potentials were far less informative. The lack of correlation between vascular and general neurological abnormalities emphasises that patients must be screened for both vascular and neurological dysfunction to prevent unrewarding vascular operation in impotent men.
\end{abstract}

\section{Introduction}

Erectile impotence is defined as the persistent inability of the patient to obtain or maintain an erection suitable for vaginal penetration and the subsequent coital act. ${ }^{1}$ Erectile impotence is commonly attributed to three main causes: vascular disease, neurological disturbances, and psychological factors. Erection requires a sufficient arterial blood supply of the corpora cavernosa arising from terminal branches of the internal pudendal artery ${ }^{2}$ and intact arteriolar sphincter mechanisms, which either fill the corpora cavernosa or shunt blood into the veins. By inflow of arterial blood into the penile sinoids these get distended and compress the draining veins against the tunica albuginea. Thus venous outflow is reduced. In the cat, Semans and Langworthy ${ }^{3}$ were able to reproduce erection, emission, and ejaculation in a normal sequence by stimulating parasympathetic, sympathetic, and somatic nerve fibres supplying the male sexual organs. Erection is mediated by efferent parasympathetic nervi erigentes arising from the S2, S3, and S4 segments of the spinal cord. Afferent somatic fibres of the pudendal nerve (S2, S3, and S4 segments) may trigger erections on local stimulation. Stimulation of sympathetic nerves (D12, L1, and L2 segments) is required for emission of seminal fluid and later detumescence. For expulsion of seminal fluid from the urethra, however, stimulation of somatic and autonomic nerve fibres of the pudendal nerve is necessary. In the absence of local stimulation, erections after cerebral stimulation may be initiated via sympathetic pathways. ${ }^{4}$ These findings indicate that normal male sexual function is critically dependent on the dynamic interplay of the parasympathetic, sympathetic, and somatic nervous system. Diagnostic urological evaluation of the erectile system has been considerably improved by the introduction of objective tests such as Doppler measurements of penile blood pressure and blood flow, ${ }^{56}$ pharmacodynamic cavernosography, ${ }^{78}$ pudendal arteriography, ${ }^{2}$ and the nocturnal penile tumescence test. ${ }^{9}$

Only during recent years have neurological test methods for the assessment of erectile nerve dysfunction become available, complementing clinical neurological investigation. These include the pudendal somatosensory evoked potentials ${ }^{112}$ and the electrically induced bulbocavernosus reflex ${ }^{13-15}$ to screen for the sensorimotor pathways and screening methods of autonomic dysfunction-sympathetic skin response, ${ }^{16} 30 / 15$ test, ${ }^{17}$ and respiratory heart rate variation. ${ }^{18} 19$

In our study 30 consecutive patients who had received a thorough urological investigation, including vascular function tests were investigated both clinically and by using an extended electrophysiological neurological test battery. We assessed the prevalence of autonomic neuropathy or other neurological disease and correlated these results to urovascular pathology.

\section{Patients and methods}

SUBJECTS AND CLINICAL INVESTIGATION

We studied 30 men aged $21-82$ years (mean 45 years; interquartile ranges: 21-38, 39-46, 47-54, and 55-82 years) complaining of complete erectile impotence for 12 months to five years. All were referred outpatients from the urological department. Each patient had a thorough medical history taken including vegetative function and drug history. Physical examination included an assessment of neurological, urogenital, and vascular abnormalities. Neurological examination placed special emphasis on possible symptoms arising from dysfunction of the spinal cord, including anal and cremaster reflexes, and the peripheral sensorimotor and autonomic nervous system. Laboratory tests included blood cell count, blood glucose and lipids (cholesterol, triglycerids), liver and kidney function, and sex hormones. The table gives further details. The results in each category were tested for linear correlation with all other categories with StatView II statistical software (Abacus Concepts 
Table Categories and tests evaluated in 30 men with erectile impotence

\begin{tabular}{|c|c|c|c|}
\hline Category & Test items & Criteria for abnormal test result & Criteria for abnormal category \\
\hline $\begin{array}{l}\text { Neuropathic risk } \\
\text { factors }\end{array}$ & $\begin{array}{l}\text { Alcohol abuse } \\
\text { Diabetes } \\
\text { Uraemia }\end{array}$ & $\begin{array}{l}>70 \mathrm{~g} \text { Ethyl-alcohol/day for }>6 \\
\text { months before examination } \\
\text { Known for }>6 \text { months } \\
\text { Known for }>6 \text { months }\end{array}$ & $\begin{array}{l}\text { One or more out of three items } \\
\text { abnormal }\end{array}$ \\
\hline $\begin{array}{l}\text { Sensorimotor } \\
\text { neuropathy }\end{array}$ & $\begin{array}{l}\text { Clinical examination } \\
\text { Motor nerve conduction (tibial } \\
\text { nerve) } \\
\text { Sensory nerve conduction (sural } \\
\text { nerve) }\end{array}$ & $\begin{array}{l}\text { Depressed tendon reflexes, distal } \\
\text { sensory loss, distal muscle wasting } \\
\text { Below mean ( } 2 \mathrm{SD} \text { ) of } 43 \mathrm{~m} / \mathrm{s} \text { (for } \\
20 \text { years) to } 35 \mathrm{~m} / \mathrm{s} \text { (for } 80 \text { years) } \\
\text { at } 33^{\circ} \mathrm{C} \\
\text { Below mean }(2 \mathrm{SD} \text { ) of } 48 \mathrm{~m} / \mathrm{s} \text { (for } \\
20 \text { years) to } 45 \mathrm{~m} / \mathrm{s} \text { (for } 80 \text { years) } \\
\text { at } 35^{\circ} \mathrm{C}\end{array}$ & $\begin{array}{l}\text { Two or more out of three items } \\
\text { abnormal }\end{array}$ \\
\hline $\begin{array}{l}\text { Autonomic } \\
\text { dysfunction }\end{array}$ & $\begin{array}{l}\text { Sympathetic skin response } \\
\text { Respiratory heart rate variation } \\
\text { 30/15 Test }\end{array}$ & $\begin{array}{l}\text { Absent from foot (all patients with } \\
\text { absent responses from hand also } \\
\text { had no responses from foot) } \\
\text { Below age related normal } \\
\text { range: }{ }^{1922} \text { for example, for } 30 \\
\text { years, } 20 / \text { min; for } 80 \text { years, } 5 / \mathrm{min} \\
\leq 1.03^{17}\end{array}$ & $\begin{array}{l}\text { Two or more out of three items } \\
\text { abnormal }\end{array}$ \\
\hline Bulbocavernosus refle & Latency & $\begin{array}{l}\text { Absent or latency above normal } \\
\text { range }(36 \mathrm{~ms} \text { for } 170 \mathrm{~cm}, 39 \mathrm{~ms} \\
\text { for } 185 \mathrm{~cm} \text { ) } \\
\text { Absent or latency above } 37.2 \mathrm{~ms}\end{array}$ & $\begin{array}{l}\text { Considered abnormal only if } \\
\text { peripheral nerve conduction } \\
\text { studies were normal } \\
\text { Considered abnormal only if } \\
\text { peripheral nerve conduction } \\
\text { studies were normal }\end{array}$ \\
\hline Vascular disease & $\begin{array}{l}\text { Doppler ultrasound of penile } \\
\text { blood flow } \\
\text { Penile cavernosogram } \\
\text { Arteriogram of pelvic arteries }\end{array}$ & & $\begin{array}{l}\text { One or more out of three tests } \\
\text { abnormal }\end{array}$ \\
\hline Vascular risk factors & $\begin{array}{l}\text { Arterial hypertension } \\
\text { Nicotine abuse } \\
\text { Diabetes mellitus } \\
\text { Elevated blood lipids } \\
\text { History of coronary heart disease }\end{array}$ & $>10$ Cigarettes/day for $>5$ years & $\begin{array}{l}\text { Two or more out of five items } \\
\text { abnormal }\end{array}$ \\
\hline $\begin{array}{l}\text { Serum levels of sex } \\
\text { hormones }\end{array}$ & $\begin{array}{l}\text { Estradiol } \\
\text { Testosterone } \\
\text { FSH } \\
\text { Prolactine }\end{array}$ & $\begin{array}{l}>80 \mathrm{pg} / \mathrm{ml} \\
<2.7 \mathrm{ng} / \mathrm{ml} \\
<1 \text { or }>14 \mathrm{U} / \mathrm{ml} \\
>14.5 \mathrm{ng} / \mathrm{ml}\end{array}$ & One or more tests abnormal \\
\hline
\end{tabular}

Inc, Berkeley, CA, USA). All investigations were carried out with informed consent and according to the Declaration of Helsinki (1975).

ELECTROPHYSIOLOGICAL INVESTIGATIONS

The 30/15 test was carried out with a conventional ECG apparatus. All other tests were performed with a Medelec MS 20 Electrophysiological System (Mystro: Medelec, Woking, UK). If electrophysiological data were compared with normal data established in the literature, care was taken to adhere to the procedures as reported.

Nerve conduction studies - Investigation of nerve conduction velocities of the sural (antidromic) and tibial nerves was performed in the conventional way with bipolar surface electrodes. The filter band pass was $20 \mathrm{~Hz}-2 \mathrm{kHz}$ for sensory nerve conduction measurements and $3 \mathrm{~Hz}-$ $10 \mathrm{kHz}$ for motor conduction measurements. The skin surface temperature from the dorsum of the foot was measured by means of a thermoelement. The normal values of nerve conduction velocities given by Ludin $^{20}$ were generally accepted and adjusted with respect to skin temperature $\left(-2 \mathrm{~m} / \mathrm{s}\right.$ for $1^{\circ} \mathrm{C}$ below the reference temperature indicated in the table).

Bulbocavernosus reflex (BCR)-The pudendal nerve was stimulated on the penis shaft by two surface ring electrodes with the anode placed distally at $80-150 \mathrm{~V}$ (stimulus duration $100-500 \mu \mathrm{s}$ ) as described by Tackmann and Porst. ${ }^{21}$ The response was recorded by means of bipolar surface electrodes (Toennies) mid- way between the scrotum and the anus. The anode was placed at the anterior superior iliacal spine. The sweep speed was set to $10 \mathrm{~ms} /$ div and the filter band pass to $10 \mathrm{~Hz}-3 \mathrm{kHz}$ : 32 sweeps were averaged. The latency was determined from the first negative deflection of the response (see figure 1). The response was considered to be abnormal if the onset latency was longer than $37.2 \mathrm{~ms}$. Normal latencies are not consistently age dependent so no correction for age was necessary.

Pudendal SEP-Stimulation ring electrodes were placed at the shaft of the penis (anode distally) as described above. The somatosensory evoked potentials were recorded from the scalp with the active needle electrode (impedance $3 \Omega$ ) placed subcutaneously $2 \mathrm{~cm}$ behind $\mathrm{Cz}$. The reference needle electrode was inserted at Fz; 300 to 800 sweeps were averaged, and each test was repeated up to three times in order to assess the reproducibility of the evoked responses. The sweep speed was set to $10 \mathrm{~ms} / \mathrm{div}$ and the filter band pass from $20 \mathrm{~Hz}$ $2 \mathrm{kHz}$. The latency of the response was measured from the P40 wave (figure 1) according to Haldeman et $a l^{1112}$ and Tackmann and Porst. ${ }^{21}$ Response onset latencies longer than the body height dependent control limits given by Tackmann and Porst ${ }^{21}$ were considered abnormal.

Respiratory heart rate variation (HRV)-The method has been described in detail in a previous article. ${ }^{19}$ Briefly, the built-in single fibre EMG-software program of the Medelec MS 20 electrophysiological system was used to 
record $50 \mathrm{RR}$ intervals (ECG) during consecutive deep inspiration and expiration cycles (6/min). Conventional ECG plate electrodes were placed on the right foot and on the left or right arm and connected to the positive and negative input sockets of the MS 20 differential preamplifier. The sweep was triggered by the QRS complex, and the ECG activity was recorded with a gain of 200 or $500 \mathrm{mV} / \mathrm{div}$, a filter band pass from $1-50 \mathrm{~Hz}$, and a sweep duration of 1-2s depending on the heart rate so that $\mathrm{QRS}$ pairs consisting of the triggering and the subsequent QRS complex could be monitored on the same sweep. The variation of the time interval between consecutive QRS complexes was assessed for $50 \mathrm{QRS}$ pairs. Variation was expressed as the difference between the frequencies calculated from the shortest and the longest $R R$ interval found within an analysis period of approximately $45 \mathrm{~s}$. In our experience HRV is almost linearly age dependent to the same extent as described by Low et al. ${ }^{22}$ The table shows our lower normal limits for the extreme ages of our patients.

Sympathetic skin response (SSR)-The biphasic skin DC-potential shift in response to electrical shock stimuli was evaluated on the right hand and foot as described by Shahani et al. ${ }^{10}$ Toennies surface electrodes were attached to the volar and dorsal side of the hand and the plantar and dorsal side of the foot. The patient was instructed to relax in order to avoid artifact contamination by tonic muscle activation. Supramaximal electrical shock stimuli were applied randomly to the median or tibial nerve of the contralateral side. Care was taken to apply the next stimulus no earlier than 20 s after the previous one in order to avoid habituation of the response. Sweep speed was set to $500 \mathrm{~ms} / \mathrm{div}$ and amplitude gain to 100 , 200 , or $500 \mu \mathrm{V} / \mathrm{div}$ as suitable. The filter band pass was set to $3 \mathrm{~Hz}-3 \mathrm{kHz}$. The response was considered to be present if clear biphasic responses could be obtained at latencies of 1-3s during several trials. If necessary, the foot was warmed up to skin surface temperatures above $28^{\circ} \mathrm{C}$ either by bathing the foot in warm water or by applying infrared light. The test was considered to be abnormal if responses were consistently absent. $^{16}$

30/15 Test-Heart rate variation in response to orthostasis was assessed as described by Ewing et al. ${ }^{17}$ The patient lay supine and relaxed and was instructed to take an upright standing position as fast as possible. The $R R$ interval between the 15th to 16 th and between the 30th to 31st QRS complex after attaining the upright position was measured and the ratio ( 30 th $/ 31$ st divided by 15 th $/ 16$ th interval) was calculated. According to Ewing ${ }^{17}$ the normal ratio is above $1 \cdot 03$. There is a tendency for older patients to have lower values than younger ones, but in our experience even older healthy people retain a ratio above 1.03 .

UROLOGICAL INVESTIGATION

This included a thorough clinical urological investigation, invasive angiography of the main pelvic arteries, and cavernosography of penile veins as well as an assessment of the penile arterial blood flow by means of Doppler ultrasound techniques and of sex hormone serum levels.

\section{Results}

CLINICAL NEUROLOGICAL INVESTIGATION

The whole test battery was performed in all $\mathbf{3 0}$ patients. Two patients were normal in all tests but had major problems that made a psychological disease the most likely factor and they were excluded from further evaluation. Clinical neurological findings were abnormal in $\mathbf{1 5}$ of the 28 remaining patients. Most showed signs of sensorimotor as well as autonomic neuropathy. No patient had signs of a cerebral lesion or of pituitary or hypothalamic dysfunction. One patient had a history of a spine trauma without residual deficits, and the occurrence of impotence was temporally unrelated to the trauma.

TYPICAL RESULTS OF ELECTROPHYSIOLOGICAI INVESTIGATIONS

The upper panel of figure 1 shows the pattern of the bulbocavernosus reflex in three patients

\section{BULBOCAVERNOSUS - REFLEX}
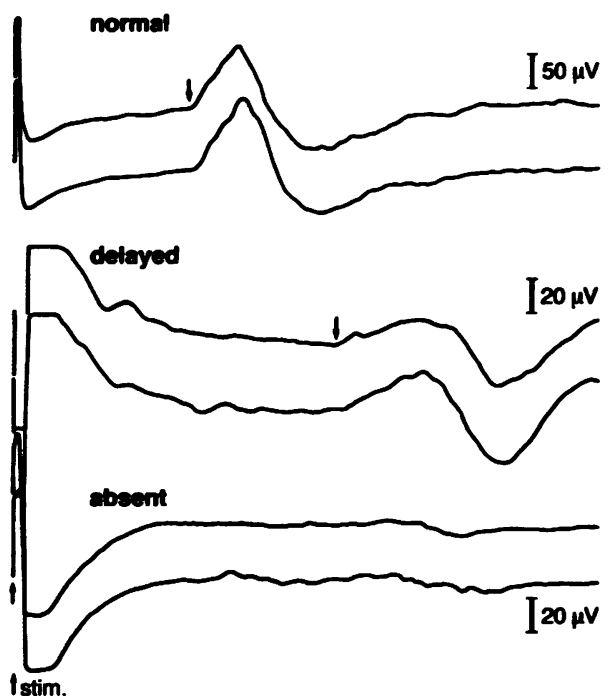

PUDENDAL - SEP

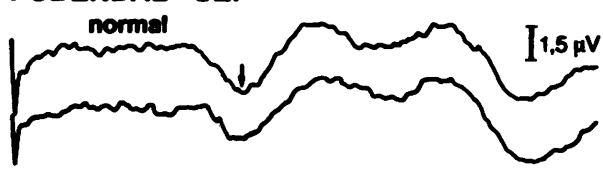

ebsent

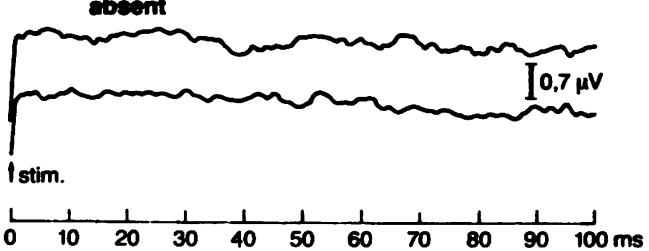

Figure 1 Examples of normal, delayed, and absent reponses for bulbocavernosus reflex measurements and pudendal SEP. For all cases two trials with 32

(bulbocavernosus reflex) and 300-500 averaged sweep (pudendal SEP) are illustrated. Points at which latencies were measured indicated by arrows. Negative is up. 
with erectile impotence. The response of patient 1 (two upper traces) was normal, that of patient 2 was delayed (traces 3 and 4 ), and in patient 3 no response was obtained (traces 5 and 6). Examples of pudendal SEP investigations are shown in the lower panel in figure 1. The pudendal SEP study of patient 1 (two upper traces) was normal, whereas in patient 3 no cortical response could be recorded (two lower traces). For the assessment of autonomic nerve function the 30/15-test, the HRV and the SSR were used. Examples are illustrated in figure 2. The upper two traces of both the upper and lower panel (patient 4) show normal SSRs recorded from the right hand and foot. Response latencies after the electrical stimulus were approximately $1 \cdot 2-2 \mathrm{~s}$. The lower traces (patient 5) show examples of absent responses. The responses from hand and foot remained absent in several trials. Examples of HRV recordings are illustrated in figure 3. Patient 4 had a normal HRV of $29 /$ min (left panel), whereas the result of patient 5 (right panel) was abnormal ( $7 / \mathrm{min})$.

INCIDENCE OF ABNORMAL FINDINGS

Clinical neurological findings, SSR in the foot, and the $30 / 15$ test were often abnormal (16 out of $30(53 \%), 16(53 \%), 17(57 \%))$ whereas the pudendal SEP was abnormal only in three (figure 4). Only one out of eight patients with abnormal bulbocavernosus reflexes had no other pathological neurological findings or neuropathic risk factors. Urological examination showed that angiography was abnormal in 21 patients (angiography of pelvic arteries in eight, arterial penile blood flow in 20) and cavernosography in eight, but serum hormone levels were abnormal in only five (figure $4 b$ ). Polyneuropathy and vascular risk factors were found in half (figure $4 \mathrm{c}$ and $\mathrm{d}$ ). Pathological

\section{SYMPATHETIC SKIN RESPONSE}

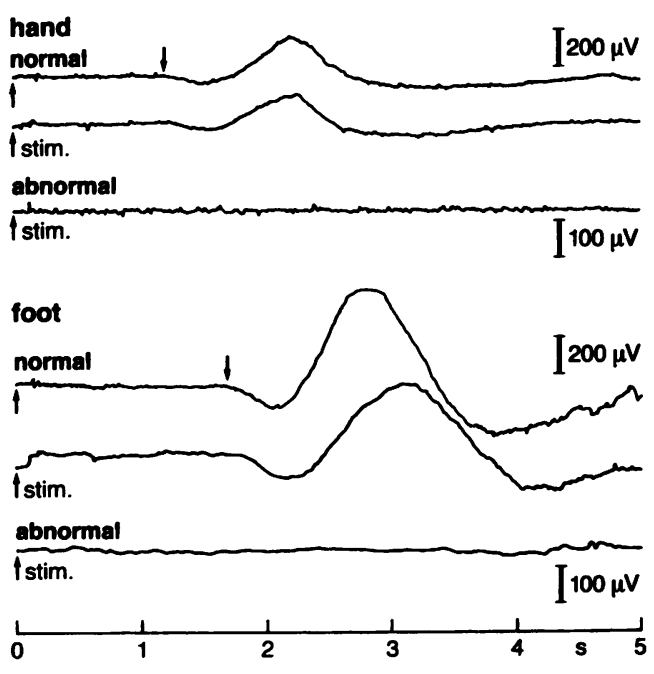

Figure 2 Examples of two patients with normal and absent sympathetic skin responses recorded in right hand and foot evoked by electrical stimuli applied

contralaterally. For patient with absent responses only one out of several sweeps illustrated. Stimulation and

beginning of responses indicated by arrows. Note long time base. findings in neurological and urovascular categories were found in 19 patients. Seven patients were affected only urologically, and three only neurologically. The upper panel of figure 5 illustrates the distribution of normal and abnormal findings among our patients for clinical neurological examination, autonomic tests and nerve conduction velocity studies. Six out of 13 patients with more than one abnormal autonomic test result were normal on clinical examination. Eleven out of 13 patients had signs of both sympathetic and parasympathetic dysfunction. The coincidence of abnormal findings in both SSR and 30/15 test was high (figure 5, lower panel). Autonomic dysfunction was more often observed than sensorimotor neuropathy (13 $v$ nine patients). None of the patients with sensorimotor neuropathy would have been missed even if nerve conduction studies had not been performed as in all these patients clinical neurological examination had already revealed abnormal findings. No significant correlations were found within the $95 \%$ confidence limits between the categories listed in the table. While most (24) patients were aged between 24 and 64 years only three out of 30 were 65 years or older. The number of pathological findings in all categories varied positively but not significantly $(p>0.05)$ with age.

\section{Discussion}

EXPERIMENTAL LIMITATIONS

There are some limits in the interpretation of our results. Firstly, our patients were referred from the urological outpatient department and may, owing to a preselection bias for urological problems, not be representative of the population of impotent men. Even in this urological selection of patients, however, a high incidence of urological and neurological abnormalities was found. The number of abnormal neurological findings would probably have been even higher in a sample of neurological patientsfor example, multiple sclerosis is a common cause of erectile impotence. A structured psychological interview and more specific psychological tests like the Minnesota multiphasic personality inventory were not used. Therefore psychological problems which were not apparent in taking the case history but contributed to the erectile impotence may have been missed. In urological practice, a confirmative answer to the question of whether there are still spontaneous erections in the morning is taken to rule out an organic cause and therefore to suggest a psychological background of erectile impotence. This was the case in two of our patients, who, in addition to normal somatic test results, had positive evidence of major psychological problems. We could not determine a simple cause and effect relationship between the organic abnormalities found and the presence of erectile impotence. Significant correlations among the categories of our test battery could not be established. A set of different tests is therefore necessary to screen for abnormalities unrelated to each other but adding up to erectile dysfunction. 
RESPIRATORY HEART RATE VARIATION
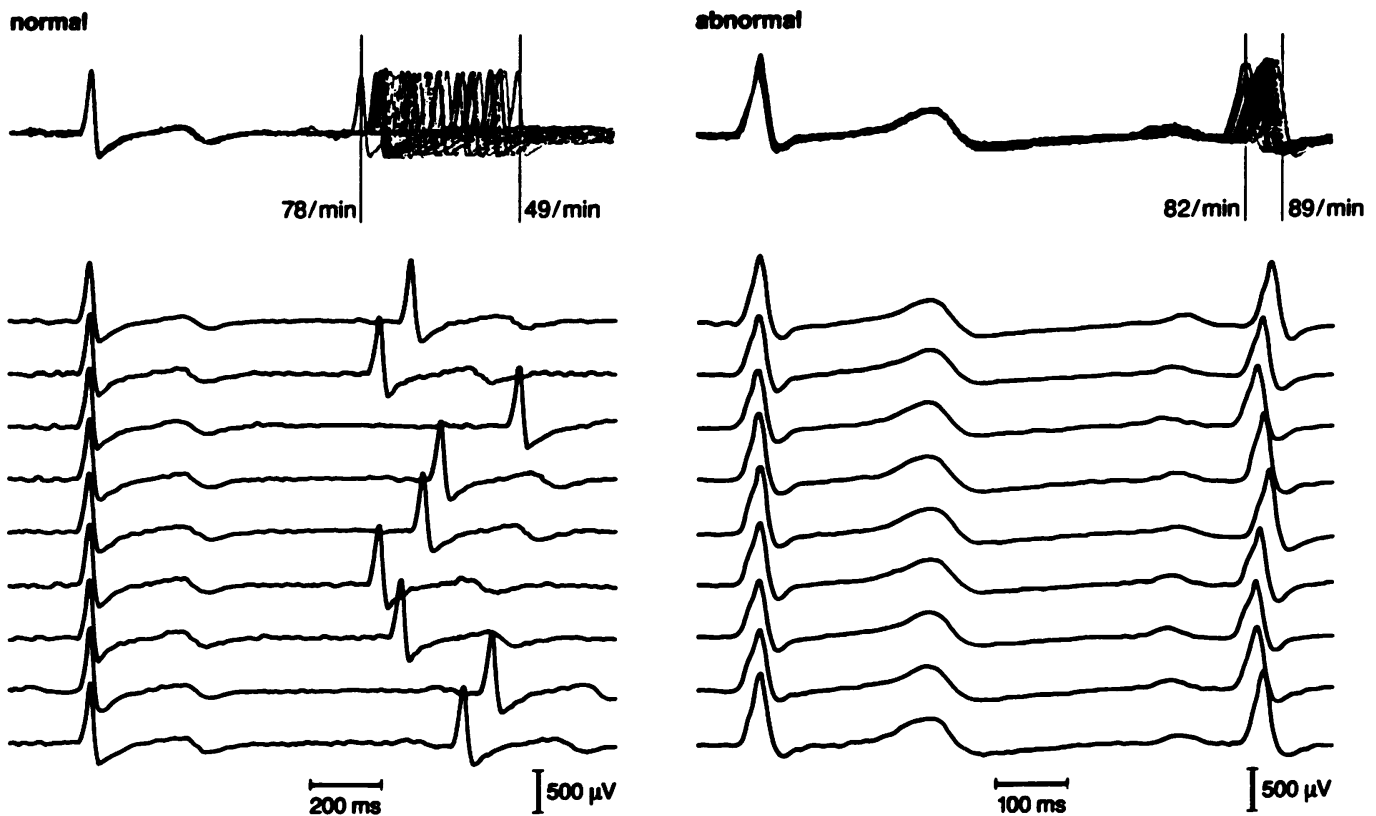

Figure 3 Examples of normal (left panel) and abnormal (right panel) heart rate variation measurements. In top traces 50 sweeps are superimposed. Position of cursors indicate minimal and maximal RR intervals, from which heart rate/min was calculated. Nine consecutive sweeps illustrating normal variability of $R R$ interval in left in contrast to right panel are shown below.
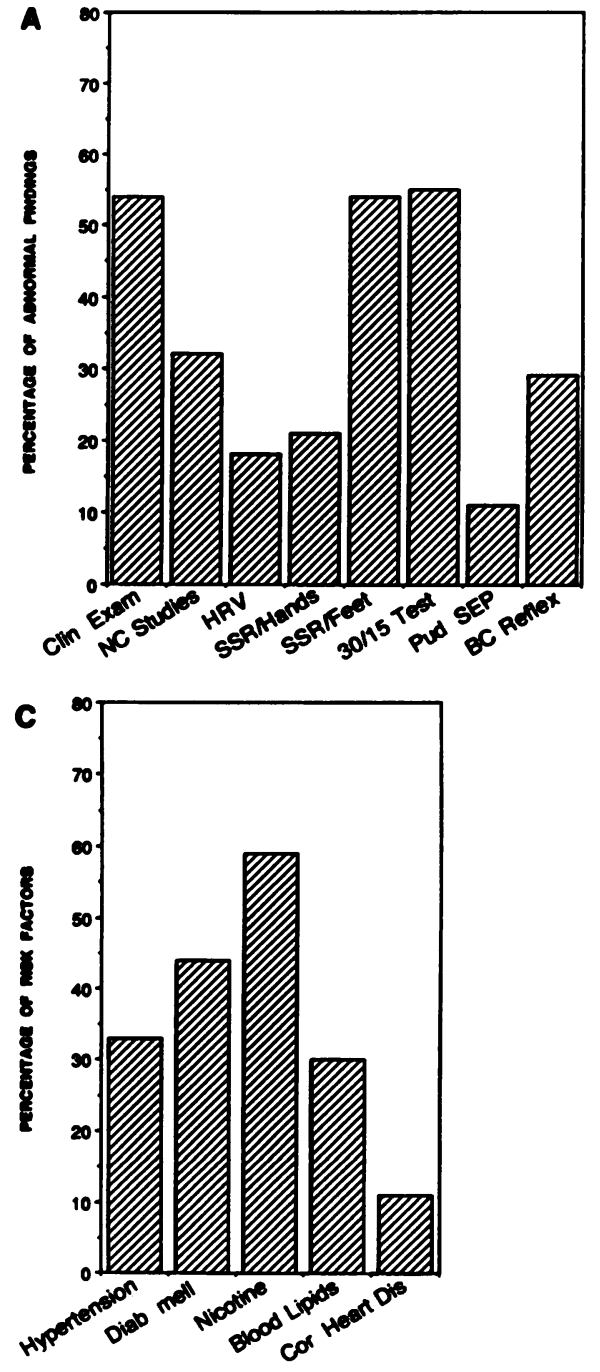

Figure 4 Percentage of abnormal findings for neurological $(A)$ and urovascular $(B)$ investigations and for risk factors for vascular disease (C) and polyneuropathy (D). Clin Exam: clinical examination; NC Studies: nerve conduction studies; HRV: respiratory heart rate variation; SSR: sympathetic skin response; Pud SEP: pudendal somatosensory evoked potentials; BC Reflex: bulbocavernosus reflex; Diab mell: diabetes mellitus; Cor Heart Dis: coronary heart disease.
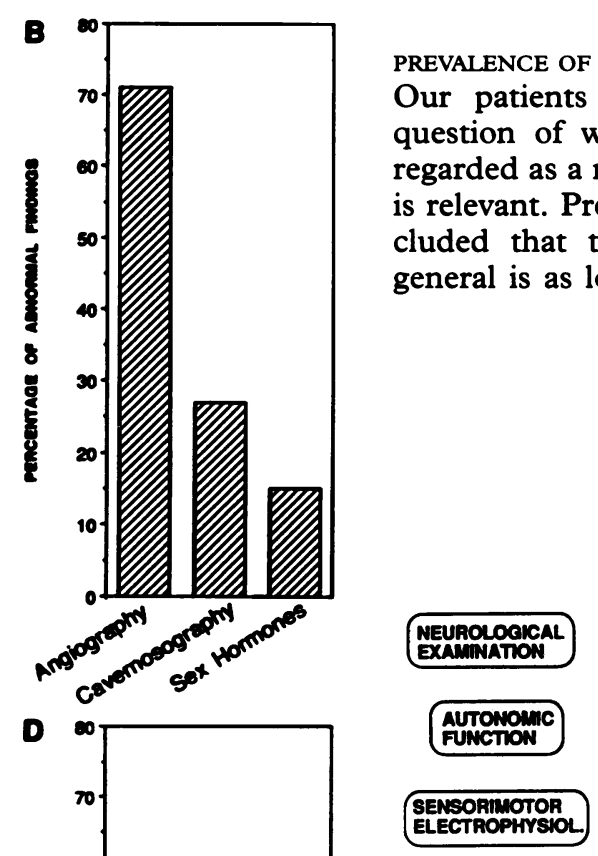

PREVALENCE OF NEUROLOGICAL ABNORMALITIES Our patients varied widely in age so the question of whether ageing itself should be regarded as a risk factor for erectile impotence is relevant. Previous studies from $1948^{23}$ concluded that the incidence of impotence in general is as low as $1.9 \%$ in 40 year old men
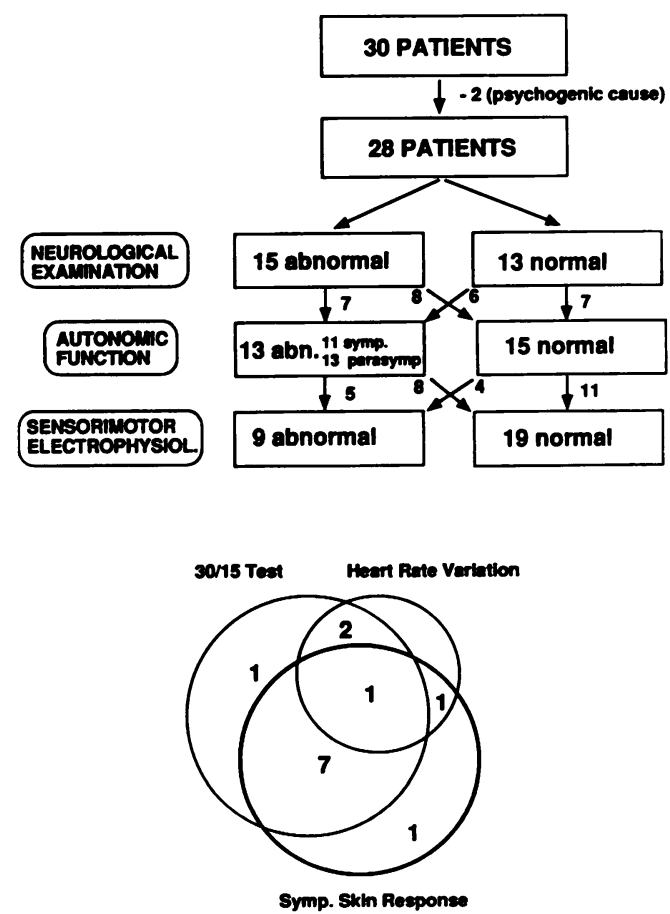

Figure 5 Numbers of patients with normal and abnormal findings in clinical neurological investigation, tests for autonomic dysfunction, and nerve conduction studies illustrated by flow chart in upper panel. Lower panel shows coincidence of abnormal findings among three autonomic tests (30/15 test, sympathetic skin response, heart rate variation). 
but $25 \%$ in 65 year old men. These figures obviously relate to a sample which was not adequately tested for urological, vascular, or neurological dysfunction. In our series the number of pathological results in all categories of neurological and urovascular dysfunction increased with age, although the correlation did not reach the $95 \%$ level of significance. Therefore, the higher proportion of impotence among older men probably results from a higher incidence of risk factors and neurological or urovascular dysfunction in older men rather than from ageing itself.

Blaivas $e t$ al $^{24}$ found abnormalities of penile blood pressure in $67 \%$, neurological abnormalities in $41 \%$, psychiatric disorders in $35 \%$, and a combination of abnormalities in $48 \%$ of their patients. The occurrence of neurological abnormalities was thus comparable to our results, even though they did not investigate autonomic nerve function electrophysiologically. In contrast, we were unable to confirm findings of Tackmann and Porst, ${ }^{21}$ who more often observed abnormalities of the bulbocavernosus reflex (BCR) (abnormal findings in 62 out of 122 patients tested) and of the pudendal SEP (abnormal in 31 out of 108 patients tested). For the BCR, similar results to ours were found by Wabrek. ${ }^{25}$ Our data indicate that investigating BCR does not add greatly to the detection of neurological deficits and is therefore not necessary in the neurological workup.

Our study confirmed the previous finding that diabetes mellitus is a major risk factor for erectile impotence. ${ }^{26}$ Whether the decisive abnormality in impotent diabetics is vascular occlusive disease ${ }^{26}$ or diabetic neuropathy is still debatable. ${ }^{27}$ The more common abnormalities of the BCR in diabetics ${ }^{28}$ highlights pudendal neuropathy as the more important factor. From our data on a urological sample of patients with erectile impotence we can draw the following conclusions. Firstly, in most impotent men both neurological and urovascular abnormalities contribute to erectile dysfunction. In contrast CNS dysfunction is rarely a cause of erectile impotence. Secondly, with more than $50 \%$ of pathological findings for each category, history and clinical neurological evaluation of the peripheral sensorimotor and autonomic nervous system (NS) have the highest yield of pathological neurological results. The SSR in the foot was abnormal in a similar proportion of patients but it is known to be rather unspecifically abnormal in elderly patients. ${ }^{22}$ Thirdly, nerve conduction studies and BCR were abnormal in a third of the patients while pudendal SEPs did not provide additional evidence in identifying erectile impotence patients with neurological problems. All patients with abnormal nerve conduction results had neuropathic findings on clinical examination. This suggests that if a neuropathy causes or contributes to erectile impotence it must be clinically overt and not just detectable electrophysiologically. Finally, autonomic tests (30/15 test and HRV for evaluation of the parasympathetic NS and SSR in the hand for the sympathetic NS) were abnormal in $64 \%$ of our patients. In most patients with signs of autonomic dysfunction abnormal results were found in both sympathetic and parasympathetic tests. More than $20 \%$ of the patients show abnormal autonomic tests in the absence of motor and somatosensory dysfunction.

DIAGNOSTIC STRATEGY AND THERAPEUTICAL IMPLICATIONS

Our results indicate that it is essential to use test screening for autonomic dysfunction. As sensorimotor polyneuropathy may mostly be detected clinically, nerve conduction studies are not always necessary. In addition, it is also unnecessary to perform a pudendal SEP in each patient. None of our patients with neurological involvement would have been missed if pudendal SEP had not been performed. We therefore suggest the following sequence of investigations in a patient with erectile impotence: exclude CNS disorders by clinical examination; evaluate peripheral NS clinically; and test autonomic sympathetic and parasympathetic NS. With erectile impotence being commonly $(68 \%)$ associated with both urological and neurological abnormalities treatment of urovascular dysfunction-for example, by revascularisation-may not be sufficient or may even not be indicated in patients with severe neurological disturbances. Also, psychological therapy alone will obviously fail. Neurological dysfunction will remain undetected if appropriate tests of sensorimotor and autonomic function are not performed. Clearly most patients with erectile dysfunction have organic deficits. Therefore it is not justified to brand them as having a psychogenic disease.

This work was supported by the Deutsche Forschungsgemeinschaft SFB 194, (A2).

1 Krane RJ, Siroky MB. Clinical neuro-urology. Boston: Little Brown and Company. 1979.

2 Ginestie JF, Romier A. Radiologic exploration of impotence. The Hague/Boston /London: Martinus Nijhoff Medical Division, 1978.

3 Semans JH, Langworthy OR. Observations on the neurophysiology of sexual functions in the male cat. $\mathcal{F}$ Urol 1938;40:836-46.

4 Root WS, Bard P. Mediation of feline erection through sympathetic pathways with some remarks on sexual senitalia. Amer $f$ Physiol 1947;151:80-90.

5 Abelson D. Diagnostic value of the penile pulse and blood pressure: a doppler study of impotence in diabetics. $\mathcal{F}$ Urol 1975;113:636-9.

6 Engel G, Burnham SJ, Carter MF. Penile blood pressure in the evaluation of erectile impotence. Fertil Steril 1978;30: $687-90$.

7 Lue TF, Hricak H, Schmidt RA, Tanagho EA. Functional evaluation of penile veins by cavernosography in papaverine-induced erection. $\mathcal{f}$ Urol 1986;135:479-82.

8 Juenemann KP, Lue TF, Fournier Jr GR, Tanagho EA. Hemodynamics of papaverine- and phentolarnineinduced penile erection. $\mathcal{F}$ Urol 1968;136:158-63.

9 Karacan I. Clinical value of noctumal erection in the progress and diagnosis of impotence. Med Aspects Hum Sex 1970;4:27-34.

10 Karacan I, Salis PJ, Ware C, et al. Nocturnal penile tumescence and diagnosis in diabetic impotence. Amer Psychiatry 1978;135:191-7.

11 Haldeman S, Bradley WE, Bhatia NN, Johnson BK Pudendal evoked responses. Arch Neurol 1982;39:280-3.

12 Haldeman S, Bradley WE, Bhatia NN. Evoked responses from the pudendal nerve. $\mathcal{F}$ Urol 1982;128:974-80.

13 Ertekin C, Reel F. Bulbocavernosus reflex in normal men and in patients with neurogenic bladder and/or impotence. F Neurol Sci 1976;28:1-15.

14 Rushworth G. Diagnostic value of the electromyographic study of reflex activity in man. Electroenceph Clin Neurophysiol (Suppl) 1967;25:65-73. 
15 Dick HC, Bradley WE, Scott FB, TImm GW. Pudendal sexual reflexes. Electrophysiologic investigations. Urology 1974;3:376-9.

16 Shahani BT, Halperin J, Boulu P, Cohen J. Sympathetic skin response: a method of assessing unmyelinated axon dysfunction in peripheral neuropathies. $\mathcal{F}$ Neurol Neurosurg Psychiatry 1984;47:536-42.

17 Ewing DJ, Campbell IW, Murray A, Neilson JMM, Clarke BF. Immediate heart-rate response to standing: simple test for autonomic neuropathy in diabetes. Brit Med $\mathcal{F}$ 1978;1:145-7.

18 Murray A, Ewing DJ, Campbell IW, Neilson JMM, Clarke BF. RR interval variation in young male diabetics. $B r$ BF. RR interval variation

19 Kunesch E, Reiners K A simple method for the routine assessment of heart-rate variation in autonomic neuropathy. Electromyogr Clin Neurophysiol 1989;29:293-7.

20 Ludin HP. Praktische Elektromyographie. Stuttgart: EnkeVerlag, 1988.

21 Tackmann W, Porst H. Diagnostik neurogener Potenzstörungen mit Hilfe des Bulbocavernosusreflexes und somatosensorisch evozierter Potentiale nach Stimulation des Nervus pudendus. Nervenarzt 1987;58:292-9.
22 Low PA, Opfer-Gehrking TL, Proper CJ, Zimmerman I. The effect of aging on cardiac autonomic and post1990;13:152-7.

23 Kinsey AC, Pomeroy W, Martin CE. Age and sexual outlet. In: Kinsey AC, Pomeroy WB, Martin CE, eds. Sexual behavior in the human male. Philadelphia: WB Saunders, 1948. 218-62.

24 Blaivas JG, O'Donnell TF, Gottlieb P, Labib KB. Comprehensive laboratory evaluation of impotent men. $f$ Urol 1980;124:201-4.

25 Wabrek AJ. Bulbocavernosus reflex testing in 100 consecutive cases of erectile dysfunction. Urology consecutive

26 Lehmann TP, Jacobs JA. Etiology of diabetic impotence. $\mathcal{f}$ Urol 1983;129:291-4.

27 Faerman I, Glocer L, Celener D, Jadzinsky M, Fox D, Rapaport M. Impotence and diabetes. Diabetes 1974;23:971-6.

28 Ertekin C, Akyürekli Ö, Nurettin A, Turgut H. The value of somatosensory-evoked potentials and bulbocavemosus reflex in patients with impotence. Acta Neurol Scand 1985;71:48-53. 